\title{
LESSON 41
}

Letters with subject headings

PAPER: A5 $(148 \times 210 \mathrm{~mm})$.

MARGINS:

Left, Pica 10; Elite 12;

Right, moved out of the way.

Turn up 10 single lines before typing this example for your folder. Type or write in the instructions as illustrated.

This may be typed in capital letters and not underscored.

Letter 16

PAPER: A5 $(148 \times 210 \mathrm{~mm})$.

MARGINS: Suitable.

TARGET TIME: 10 minutes.

Turn up 10 single lines before starting.

Letter 17

PAPER: A5 $(148 \times 210 \mathrm{~mm})$.

MARGINS: Suitable.

TARGET TIME: 10 minutes.

Turn up 10 single lines before starting.
If a letter has a subject heading this is typed 2 single-line spaces below the salutation, at the left hand margin. Turn up 2 single-line spaces after the subject heading, before you start the letter. Unless the last word of the subject heading is abbreviated, do not put a full stop at the end of it. If you do have to use a full stop, do not underscore it.

To-day's date

(Turn up 3 single lines)

R. Sleath \& Co. Ltd.,

47 Bridge Street,

Barnsley. BA5 6BS

(Turn up 3 single lines)

Dear Sirs,

(Turn up 2 single lines)

Quotation for decorating premises

(Turn up 2 single lines)

With reference to your request etc.

Ref. SF/HH To-day's date

Miss C. Truselle, 12 Holly Lane, Yeovil. YE6 7LA

Dear Miss Truselle,

HOLIDAYS IN SPAIN

Thank you for your recent enquiry concerning winter Holidays in Spain. (Paragraph)

Full details of all our Holidays in spain from October to March are given in the enclosed brochure. You will observe that we offer party reductions.

Yours faithfully, CONTINENTAL TRAVEL

Sid Foster Booking Manager

Enc.

Ref. PC/FO Asfor despatel to-day

Mis. M. Cooke, 81 churder street, Cirencesters. CI/x 8SE Dear madam, your Order no. 3k2

We are pleased to inform you that your Order $n_{0} .342$ for a drees and coat is now ready for collection. (Paragrapo) We are closed all day on wedres day but remain open uncil 1900 hous on Friday. yous faitafully, Pat Caswell manageress 